\title{
First time molecular detection and phylogenetic relationships of torque teno sus virus 1 and 2 in domestic pigs in Uganda: further evidence for a global distribution
}

Matilda Brink ${ }^{1}$, Karl Ståhl ${ }^{1}$, Charles Masembe ${ }^{2}$, Ademun Rose Okurut ${ }^{3}$, Mikael Berg ${ }^{1}$ and Anne-Lie Blomström ${ }^{1 *}$

\begin{abstract}
Background: Torque teno sus virus 1 (TTSuV1) and 2 (TTSuV2) are small, single-stranded circular DNA viruses belonging to the Anelloviridae family. Available studies clearly show that both viruses are widely distributed in the pig populations in America, Europe and Asia, although the impact of the infection is still unclear. Currently, the situation in domestic pig populations on the African continent is not known. Therefore, the aim of this study was to investigate the possible presence of the two viruses in domestic pigs in Uganda, and describe the phylogenetic relationships to those in the rest of the world.

Results: Ninety-five serum samples from six districts in Uganda were used, and PCR using TTSuV1 and 2 specific primers for the UTR region was run for viral nucleic acid detection. The positive samples were sequenced, and phylogenetic analyses performed in order to compare the Ugandan sequences with sequences from other parts of the world. The prevalence of TTSUV1 and 2 in the selected domestic pigs were estimated at $16.8 \%$ and $48.4 \%$ respectively, with co-infection found in 13.7\%. The sequence identity was 90-100\% between the Ugandan TTSuV1; and $63-100 \%$ between the Ugandan TTSuV2 sequences.
\end{abstract}

Conclusion: This is the first report on the presence of TTSuV1 and 2 in domestic pigs in Uganda. These results highlight the importance of screening for emerging viruses given the globalisation of human activities.

Keywords: Torque teno sus virus (TTSuV), phylogenetic analysis, Uganda

\section{Background}

Torque teno virus (TTV) is a small non-enveloped, circular, single-stranded DNA virus belonging to the Anelloviridae family. It was first discovered in 1997 in a patient with post-transfusion hepatitis [1,2], but has since then been found in a number of species including chimpanzees, dogs, cattle and pigs [3]. The involvement of TTV in different diseases has been investigated but so far no clear connection has been shown; the role of TTV, if any, is complicated by the fact that the virus seems to be part of the normal viral flora in most investigated species [3-5].

\footnotetext{
* Correspondence: anne-lie.blomstrom@slu.se

'Section of Virology, Department of Biomedical Sciences and Veterinary

Public Health, Swedish University of Agricultural Sciences, Uppsala, Sweden

Full list of author information is available at the end of the article
}

TTV was first discovered in pigs in 1999 [6] but a retrospective study from Spain showed that the virus had been present at least since 1985 [7]. Genetic analyses distinguished two genogroups, TTV-1 and TTV-2 [8], which recently were proposed to be redefined as two separate species, Torque teno sus virus 1 (TTSuV1) and 2 (TTSuV2), due to the low sequence identity shown $[9,10]$. The presence of TTSuV1 has been investigated in a number of countries in Europe, North America and Asia with prevalences ranging between $9-100 \%$ in the studied populations $[6,7,11-14]$. Studies of TTSuV2 have shown prevalences in the same range [7,13-15]. TTSuV has been demonstrated in European wild boar [16], and co-infection with both TTSuV1 and 2 is a common finding, in wild boar as well as in domestic pigs.

\section{C) Biomed Central}

(C) 2011 Brink et al; licensee BioMed Central Ltd. This is an Open Access article distributed under the terms of the Creative Commons Attribution License (http://creativecommons.org/licenses/by/2.0), which permits unrestricted use, distribution, and reproduction in any medium, provided the original work is properly cited. 
Thus, studies clearly show that TTSuV1 and TTSuV2 are widely distributed in domestic pigs in America, Europe and Asia, but the situation in domestic pig populations on the African continent is not known. In this pilot study we performed a first investigation of TTSuV1 and 2 distributions in Uganda.

\section{Results}

\section{Detection of TTSuV1 and TTSuV2}

TTSuV was detected in pigs from all the six different districts (Figure 1) investigated and in total TTSuV was detected in $51.6 \%$ (49/95 samples positive for either of viruses or both) of the serum samples. TTSuV1 was found in 16 out of 95 samples (16.8\%) and TTSuV2 in 46 out of 95 samples (48.4\%). Co-infection with both species was seen in 13 out of 95 samples (13.7\%).

\section{Genetic and phylogenetic studies of TTSuV1 and 2 UTR sequences}

The sequences from the PCR products of 14 TTSuV1 and 32 TTSuV2 positive serum samples were used for diversity and phylogenetic studies. All the sequences have been deposited in the GenBank: accession number JN191451-96.

The TTSuV1 sequences in this study showed a sequence similarity of $90-100 \%$ to each other. When

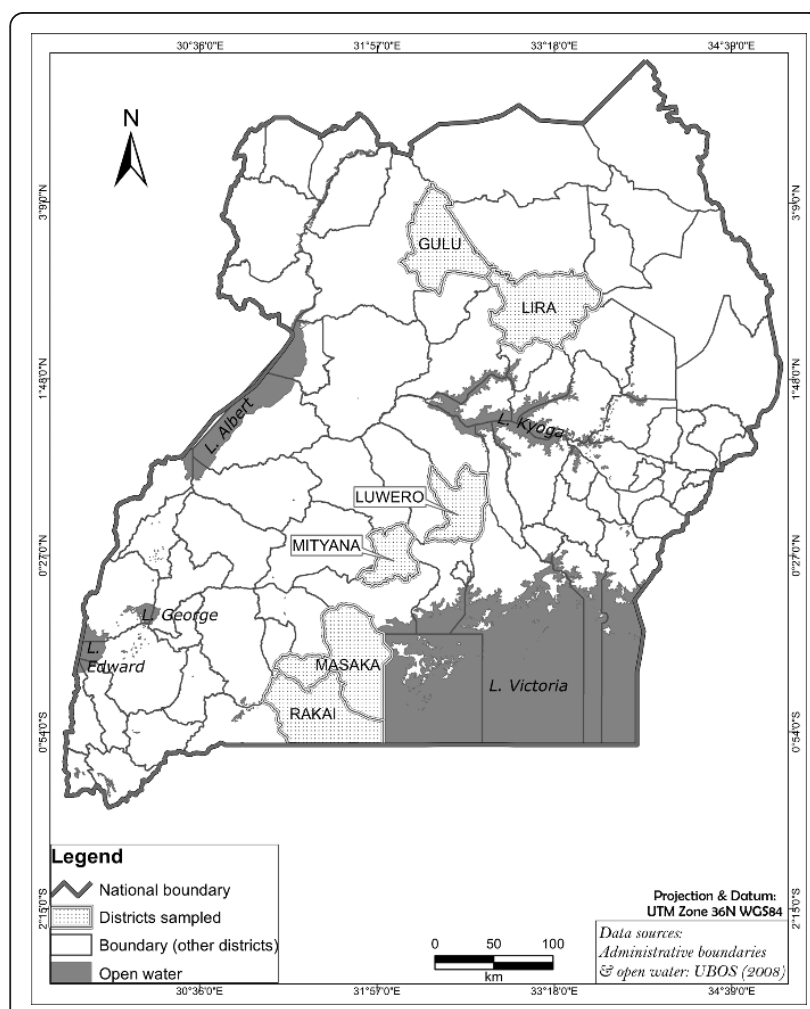

Figure 1 Map of Uganda. Map of Uganda showing the six districts where the samples were collected. compared to 38 TTSuV1 sequences originating from other parts of the world, the identity ranged from 90 to $98 \%$. The phylogenetic analysis of the TTSuV1 sequences (Figure 2) shows no unique geographical clustering of the Ugandan sequences.

The Ugandan TTSuV2 sequences displayed a higher sequence divergence with pair wise similarities between $63-100 \%$. When compared to 44 TTSuV2 sequences from America, Asia and Europe the pair wise similarities ranged between 64-99\%. No clear geographical grouping was seen (Figure 3). The phylogenetic tree displayed two main clades, with separation due to an 11-12 nt long region present in the sequences forming one of the clades. Within this group three of the Ugandan sequences (JN191494, JN191482 and JN191483) had an additional $20 \mathrm{nt}$ long region a bit further downstream from the first region and these do therefore group on a well-supported sub-clade.

\section{Discussion}

This is the first study investigating the presence of TTSuV1 and 2 in domestic pigs in Uganda, and indeed on the African continent. Available studies from many parts of the world demonstrate that these viruses are widespread among pig populations [3,17], and it is therefore not surprising to see the same pattern in Ugandan pigs: our study showed that around half of the investigated domestic pigs were infected with either of the TTSuV species, indicating that TTSuV infection is common in Uganda. TTSuV1 was detected in fewer pigs compared to TTSuV2, and in most (13/16) of the samples positive for TTSuV1, TTSuV2 was also detected. Whereas TTSuV2 was detected in similar frequencies as in previous comparable studies $[12,18,19]$, the detected prevalence of TTSuV1 positive pigs was lower compared to what has been reported elsewhere $[11,12,19,20]$.

The genetic similarity of the sequenced Ugandan TTSuV UTR regions was higher for TTSuV1 than for TTSuV2 (TTSuV1: 90-100\%; TTSuV2: 63-100\%). The sequence identity to sequences from other parts of the world displayed a similar pattern (TTSuV1: 90-98\%; TTSuV2: 64-99\%). Previous studies have shown that TTSuV lacks an apparent geographical clustering when studying the UTR region [11]. The phylogenetic analysis of TTSuV1 (Figure 2) displays the Ugandan sequences evenly distributed among the isolates from other parts of the world. TTSuV2 also grouped evenly together with the sequences from other parts of the world (Figure 3). A grouping of the sequences into two clades was due to an 11-12-nucleotide long region present in a number of sequences (a similar result was obtained by using Maximum Likelihood based on the Tamura-Nei model (data not shown)). An additional 20-nucleotide long region was present in three of the Ugandan isolates and these 


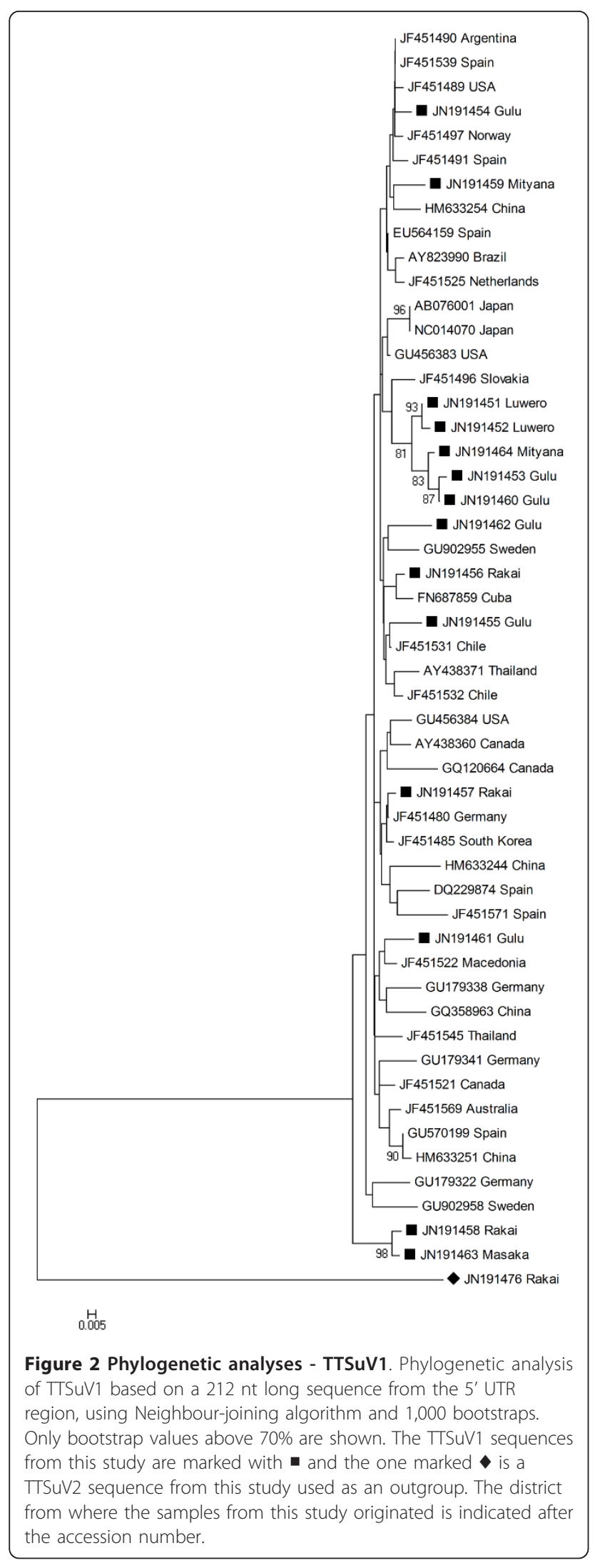

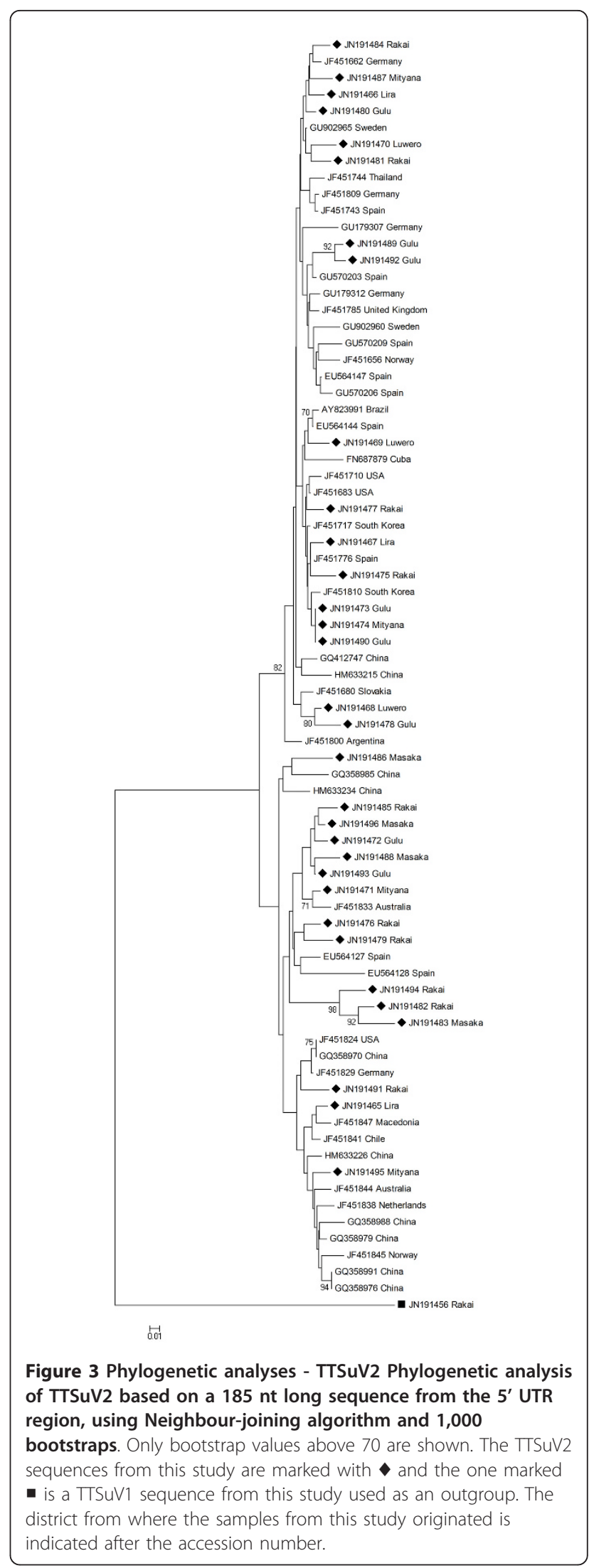


therefore formed a well-supported sub-clade. Overall, the bootstrap values within the clades were generally low for both genotypes, meaning that branching patterns of these are not always highly confident. Using the ORF1 capsid gene as a marker, which has been suggested previously [7], could possibly give a better idea of the evolutionary origin of the sequences, since the capsid gene presumably is under purifying selection. Also using the complete genome would be valuable for phylogenetic analysis $[9,10]$ to investigate possible episodes of viral introduction(s) and relations to epidemiological events.

The potential pathogenicity of TTSuV is unclear, but it is speculated that these viruses can be directly or indirectly involved in disease development. Several studies in pigs concern the role of co-infection of TTSuV1 and 2 with known pathogenic viruses like PCV-2, the causative agent of PMWS [13,19,21]. Although two of these studies indicate a somewhat higher co-infection rate of TTSuV in diseased pigs further studies are needed to prove the involvement of TTSuV in PMWS pathogenesis. 18 out of the 95 samples in the present study had previously been tested positive for African swine fever virus, but the proportion of TTSuV1 and 2 positives among these 18 samples did not differ significantly from that of the entire sample (data not shown).

\section{Conclusion}

In conclusion, the present study is the first in assessing the presence of TTSuV in domestic pigs on the African continent. In this limited study we have shown that, like in other parts of the world, TTSuV1 and 2 seem to be widespread among domestic pigs in Uganda.

\section{Methods}

\section{Samples}

Serum samples from 95 domestic pigs in Uganda were used in this study. The samples were collected from 70 pig farms in six different districts in Uganda - Gulu, Lira, Luwero, Masaka, Mityana and Rakai (Figure 1) during the years 2010 and 2011, as part of an in-depth research project on African swine fever epidemiology. Half of the samples originated from farms with suspected outbreaks of African swine fever, and half from farms with no clinical signs of the disease. The Ministry of Agriculture Animal Industry and Fisheries together with Makerere University are mandated to carry out animal disease investigations in the country. This is done by veterinarians who handle the animals under internationally recognized guidelines.

\section{DNA extraction}

The majority of the serum samples were extracted using DNeasy Blood \& Tissue kit (Qiagen, Hilden,
Germany) according to the protocol "Purification of Total DNA from Animal Blood or Cells" provided by the manufacturer. 200 microliter serum was used from each sample and the DNA was eluted in $100 \mu \mathrm{l} \mathrm{AE}$ buffer. A few of the samples were extracted through combining TRIzol (Invitrogen, Carlsbad, CA, USA), back extraction buffer (4 M Guanidine Thiocyanate, 50 mM Sodium Citrate, $1 \mathrm{M}$ Tris) and QIAamp DNA mini kit (Qiagen, Hilden, Germany). After removing the RNA phase from the serum/TRIzol/chloroform mixture, $750 \mu$ l back extraction buffer was added. The samples were then mixed by inversion for $3 \mathrm{~min}$ and centrifuged for $30 \mathrm{~min}$ at $12000 \times \mathrm{g}$. The aqueous upper phase containing DNA was transferred to a new tube and mixed with the same volume $70 \%$ ethanol before loading it onto a DNeasy Mini Spin Column and centrifuged at $12000 \times \mathrm{g}$ for $30 \mathrm{~s}$. The column was washed with $500 \mu \mathrm{l} \mathrm{AW} 1$ and AW2 buffer, respectively, and the DNA was finally eluted in $50 \mu \mathrm{l}$ AE buffer. The extracted DNA was stored in $-20 \mathrm{C}$ until further use.

\section{TTSuV1 and 2 detection and partial sequencing}

TTSuV1 and TTSuV2 were detected by PCR using primers specific for the UTR of the respective viral genome [7]. Each reaction consisted of $1 \times$ PCR buffer, $2.5 \mathrm{mM}$ $\mathrm{MgCl}_{2}, 1.0 \mathrm{mM} \mathrm{dNTP}, 0.4 \mu \mathrm{M}$ forward primer and reverse primer each, and 1.25 U AmpliTaq Gold DNA polymerase (Applied Biosystems, Foster City, CA, USA). Two or four $\mu$ l DNA, depending on the DNA concentration achieved from the two different extraction methods, was used as template. Amplification was performed with the following reaction conditions: a 12 min enzyme activation step at $95 \mathrm{C}$ followed by 39 cycles of $95 \mathrm{C}$ for $30 \mathrm{~s}, 58 \mathrm{C}$ for $30 \mathrm{~s}$ and $72 \mathrm{C}$ for $90 \mathrm{~s}$, finishing with one cycle for $10 \mathrm{~min}$ of $72 \mathrm{C}$. The PCR products were visualized on a $1.3 \%$ agarose gel. The PCR positive products were purified using the QIAquick PCR purification kit (Qiagen, Hilden, Germany) according to the manufactures' instructions and eluted in $30 \mu \mathrm{l}$ EB. The purified products were sent to Macrogen Inc. (Seoul, Korea) for Sanger sequencing.

\section{Phylogenetic studies}

The chromatograms were edited in SeqMan (Lasergene 9, DNASTAR Inc., Madison, USA). The edited sequences were subsequently aligned by ClustalW in BioEdit http://www.mbio.ncsu.edu/bioedit/bioedit.html and the sequence identity was compared. The phylogenetic relationship among the TTSuV1 and TTSuV2 sequences from this study were compared to previously published sequences available from GenBank http:// www.ncbi.nlm.nih.gov/genbank using Mega 5 [22] for the construction of a phylogenetic tree using the 
Neighbour-joining algorithm with the p-distance substitution model and with a bootstrap value of 1000 .

\section{Acknowledgements}

We would like to thank the District Veterinary Officers and field support staff in the included districts for assistance during sampling, and our colleagues Denis Muhangi and Susan Ndyanabo for technical assistance in the lab and in the field. Financial support for this study was obtained from the Swedish International Development Cooperation Agency (Sida; SWE-2009-081), the research Council Formas (221-2009-1984) and the Swedish Ministry of Foreign Affairs as part of its special allocation on global food security (through the Swedish University of Agricultural Sciences, SLU)

\section{Author details}

'Section of Virology, Department of Biomedical Sciences and Veterinary Public Health, Swedish University of Agricultural Sciences, Uppsala, Sweden. ${ }^{2}$ College of Natural Sciences, Makerere University, Kampala, Uganda. ${ }^{3}$ Ministry of Agricultural Animal Industry and Fisheries, Entebbe, Uganda.

\section{Authors' contributions}

$\mathrm{MaB}$ has performed the laboratory experiments and contributed to the data analysis and drafting of the manuscript. KS and CM coordinated the field work and contributed to study design, data analysis and final manuscript preparation. ARO were involved in field work and final manuscript preparation. MiB contributed to study design, data analysis and final manuscript preparation. ALB contributed to laboratory analysis, study design, data analysis, manuscript draft and final manuscript preparation. All authors have read and approved the final manuscript.

\section{Competing interests}

The authors declare that they have no competing interests.

Received: 5 July 2011 Accepted: 15 February 2012

Published: 15 February 2012

\section{References}

1. Nishizawa T, Okamoto H, Konishi K, Yoshizawa H, Miyakawa Y, Mayumi M: A novel DNA virus (TVV) associated with elevated transaminase levels in posttransfusion hepatitis of unknown etiology. Biochem Biophys Res Commun 1997, 241:92-97.

2. Okamoto H, Nishizawa T, Kato N, Ukita M, Ikeda H, lizuka H, Miyakawa Y, Mayumi M: Molecular cloning and characterization of a novel DNA virus (TTV) associated with posttransfusion hepatitis of unknown etiology. Hepatol Res 1998, 10:1-16.

3. Okamoto H: TT viruses in animals. Curr Top Microbiol Immunol 2009, 331:35-52.

4. Bendinelli M, Pistello M, Maggi F, Fornai C, Freer G, Vatteroni ML: Molecular properties, biology, and clinical implications of $\Pi T$ virus, a recently identified widespread infectious agent of humans. Clin Microbiol Rev 2001, 14:98-113

5. Hino S, Miyata H: Torque teno virus (TTV): current status. Rev Med Virol 2007, 17:45-57.

6. Leary TP, Erker JC, Chalmers ML, Desai SM, Mushahwar IK: Improved detection systems for $T \pi$ virus reveal high prevalence in humans, nonhuman primates and farm animals. J Gen Virol 1999, 80(Pt 8):2115-2120.

7. Segales J, Martinez-Guino L, Cortey M, Navarro N, Huerta E, Sibila M, Pujols J, Kekarainen T: Retrospective study on swine Torque teno virus genogroups 1 and 2 infection from 1985 to 2005 in Spain. Vet Microbiol 2009, 134:199-207.

8. Niel C, Diniz-Mendes L, Devalle S: Rolling-circle amplification of Torque teno virus (TTV) complete genomes from human and swine sera and identification of a novel swine TTV genogroup. J Gen Virol 2005, 86:1343-1347.

9. Cortey M, Macera L, Segales J, Kekarainen T: Genetic variability and phylogeny of Torque teno sus virus 1 (TSSV1) and 2 (TTSuV2) based on complete genomes. Vet Microbiol 2011, 148:125-131.

10. Huang YW, Ni YY, Dryman BA, Meng XJ: Multiple infection of porcine Torque teno virus in a single pig and characterization of the full-length genomic sequences of four U.S. prototype PTTV strains: implication for genotyping of PTTV. Virol 2010, 396:289-297.

11. McKeown NE, Fenaux M, Halbur PG, Meng XJ: Molecular characterization of porcine $\Pi$ virus, an orphan virus, in pigs from six different countries. Vet Microbiol 2004, 104:113-117.

12. Martelli F, Caprioli A, Di Bartolo I, Cibin V, Pezzotti G, Ruggeri FM, Ostanello F: Detection of swine torque teno virus in Italian pig herds. J Vet Med B Infect Dis Vet Public Health 2006, 53:234-238.

13. Blomström AL, Belak $S$, Fossum $C$, Fuxler L, Wallgren P, Berg M: Studies of porcine circovirus type 2 , porcine boca-like virus and torque teno virus indicate the presence of multiple viral infections in postweaning multisystemic wasting syndrome pigs. Virus res 2010, 152:59-64.

14. Zhu CX, Cui L, Shan TL, Luo XN, Liu ZJ, Yuan CL, Lan DL, Zhao W, Liu ZW, Hua XG: Porcine torque teno virus infections in China. J clin Virol: the official publication of the Pan American Soc $f$ Clin Virol 2010, 48:296-298.

15. Gallei A, Pesch S, Esking WS, Keller C, Ohlinger VF: Porcine Torque teno virus: determination of viral genomic loads by genogroup-specific multiplex rt-PCR, detection of frequent multiple infections with genogroups 1 or 2, and establishment of viral full-length sequences. Vet Microbiol 2010, 143:202-212.

16. Martinez L, Kekarainen T, Sibila M, Ruiz-Fons F, Vidal D, Gortazar C, Segales J: Torque teno virus (TTV) is highly prevalent in the European wild boar (Sus scrofa). Vet Microbiol 2006, 118:223-229.

17. Kekarainen $\mathrm{T}$, Segales J: Torque teno virus infection in the pig and its potential role as a model of human infection. Vet J 2008, 180(2):163-168

18. Kekarainen T, Lopez-Soria S, Segales J: Detection of swine Torque teno virus genogroups 1 and 2 in boar sera and semen. Theriogenology 2007, 68:966-971.

19. Kekarainen T, Sibila M, Segales J: Prevalence of swine Torque teno virus in post-weaning multisystemic wasting syndrome (PMWS)-affected and non-PMWS-affected pigs in Spain. J Gen Virol 2006, 87:833-837.

20. Bigarre L, Beven V, de Boisseson C, Grasland B, Rose N, Biagini P, Jestin A: Pig anelloviruses are highly prevalent in swine herds in France. J Gen Virol 2005, 86:631-635.

21. Ellis JA, Allan G, Krakowka S: Effect of coinfection with genogroup 1 porcine torque teno virus on porcine circovirus type 2-associated postweaning multisystemic wasting syndrome in gnotobiotic pigs. Am J Vet Res 2008, 69:1608-1614.

22. Tamura K, Dudley J, Kumar S: Molecular Evolutionary Genetics Analysis (MEGA) software version 4.0. Mol Evol Genetics Anal (MEGA) software version 40 2007, 24:1596-1599.

doi:10.1186/1743-422X-9-39

Cite this article as: Brink et al: First time molecular detection and phylogenetic relationships of torque teno sus virus 1 and 2 in domestic pigs in Uganda: further evidence for a global distribution. Virology Journal 2012 9:39.

\section{Submit your next manuscript to BioMed Central and take full advantage of:}

- Convenient online submission

- Thorough peer review

- No space constraints or color figure charges

- Immediate publication on acceptance

- Inclusion in PubMed, CAS, Scopus and Google Scholar

- Research which is freely available for redistribution

Submit your manuscript at www.biomedcentral.com/submit
C Biomed Central 